\title{
Different origins of visible luminescence in ZnO nanostructures fabricated by the chemical and evaporation methods
}

\author{
D. Li, Y. H. Leung, A. B. Djurišić, ${ }^{a)}$ Z. T. Liu, M. H. Xie, S. L. Shi, and S. J. Xu \\ Department of Physics, The University of Hong Kong, Pokfulam Road, Hong Kong, China \\ W. K. Chan \\ Department of Chemistry, The University of Hong Kong, Pokfulam Road, Hong Kong, China
}

(Received 15 March 2004; accepted 25 June 2004)

\begin{abstract}
We prepared $\mathrm{ZnO}$ nanostructures using chemical and thermal evaporation methods. The properties of the fabricated nanostructures were studied using scanning electron microscopy, x-ray diffraction, photoluminescence, and electron paramagnetic resonance (EPR) spectroscopy. It was found that the luminescence in the visible region has different peak positions in samples prepared by chemical and evaporation methods. The samples fabricated by evaporation exhibited green luminescence due to surface centers, while the samples fabricated by chemical methods exhibited yellow luminescence which was not affected by the surface modification. No relationship was found between green emission and $g \sim 1.96$ EPR signal, while the sample with yellow emission exhibited strong EPR signal. (C) 2004 American Institute of Physics. [DOI: 10.1063/1.1786375]
\end{abstract}

$\mathrm{ZnO}$ is of great interest for photonic applications, and thus, the optical properties of different forms of $\mathrm{ZnO}$ (single crystals, thin films, powder, and nanostructures) have been extensively studied. ${ }^{1-23} \mathrm{ZnO}$ typically exhibits UV band edge emission and a broad visible band due to defect emission. The visible photoluminescence (PL) is most commonly green, ${ }^{1-7}$ though other peaks such as, for example, orange ${ }^{8}$ and yellow emission ${ }^{14,15,17-19}$ have also been reported. Out of different reported emission peaks, the origin of the green emission is the most controversial one. It was proposed that green emission in $\mathrm{ZnO}$ originates from $\mathrm{Cu}$ impurities.,4 However, the dependence of the PL spectra on the fabrication atmosphere ${ }^{9}$ and the annealing conditions ${ }^{10}$ may be more consistent with an intrinsic defect than an extrinsic impurity. Vanheusden et al. ${ }^{1,2}$ observed a correlation between the intensities of $g \approx 1.96$ electron paramagnetic resonance (EPR) peak and green photoluminescence (PL) and proposed that the green PL originates from a transition between singly charged oxygen vacancy and photoexcited hole. However, the assignment of $g \sim 1.96$ signal to singly ionized oxygen vacancy is controversial. This signal was also assigned to shallow donors, ${ }^{3,24,25}$ regardless of the shallow donor identity, ${ }^{24}$ and free electrons, ${ }^{26}$ while $g_{\perp}=1.9945$ and $g_{\|}$ $=1.9960$ signals were assigned to singly ionized oxygen vacancy $V_{o}^{+3,24}$ Furthermore, theoretical predictions indicate that the native shallow donor in $\mathrm{ZnO}$ is interstitial zinc $\mathrm{Zn}_{i}$ while oxygen vacancy is a deep donor. ${ }^{27}$ Therefore, the hypothesis of correlation between green PL and presence of oxygen vacancies based on $g \sim 1.96$ EPR signal is likely not correct.

Other proposed mechanisms include transition between the electron close to the conduction band and deeply trapped hole at $V_{o}^{++}$center (oxygen vacancy containing no electrons), ${ }^{11,12,16}$ donor-acceptor and shallow donor-deep level transitions, ${ }^{5-7}$ zinc interstitials ${ }^{15}$ and antisite oxygen. ${ }^{13}$ It is possible that visible luminescence in $\mathrm{ZnO}$ has different origins in different samples. For example, single crystals and

\footnotetext{
a)Electronic mail: dalek@hkusua.hku.hk
}

phosphor powders may be more likely to exhibit impurity related emission, while nanostructures and epitaxial thin films are more likely to exhibit emission due to intrinsic defects. In this work, we attempt to clarify the origins of visible emissions in $\mathrm{ZnO}$ nanostructures fabricated by different methods. We performed EPR and PL measurements for $\mathrm{ZnO}$ samples prepared using chemical procedure (from aqueous solution of zinc nitrate hydrate and hexamethylenetetramine $)^{17}$ and evaporation procedure by oxidation of $\mathrm{Zn}$ (in humid argon and dry nitrogen flow) as reported previously ${ }^{9}$ or by heating a mixture of $\mathrm{ZnO}$ and graphite $(1: 1 \text { molar ratio })^{21}$ at $1100^{\circ} \mathrm{C}$ in a tube furnace.

The structure of deposited materials was investigated by x-ray diffraction (XRD) using Siemens D5000 x-ray diffractometer, and energy dispersive $\mathrm{x}$-ray spectroscopy (EDX) and scanning electron microscopy (SEM) using Leo 1530 FESEM. EPR measurements were performed using Bruker EMX EPR Spectrometer. The room temperature and $4 \mathrm{~K} \mathrm{PL}$ spectra were measured using a $\mathrm{HeCd}$ laser excitation source $(325 \mathrm{~nm})$. Figure 1 shows the representative SEM images of $\mathrm{ZnO}$ nanostructures fabricated by a chemical method [Figs. 1(a) and 1(b) and evaporation in humid argon flow [Fig. 1(c)]. Nitrogen gas flow yielded the same morphology as humid argon flow. For $\mathrm{ZnO}$ :graphite mixture, tetrapod structures similar to those reported in our previous study ${ }^{9,21}$ were obtained (not shown). XRD spectra in all cases show peaks corresponding to wurtzite $\mathrm{ZnO}$. No diffraction peaks from $\mathrm{Zn}$ or other impurities were detected. Figure 2 shows the EPR spectra from different samples, while the comparison of the corresponding PL spectra is shown in Fig. 3(a). It can be observed that the strong $g \sim 1.96$ EPR signal is present only for the sample prepared by chemical methods which exhibits yellow instead of green photoluminescence. Other samples show weak or no $g \sim 1.96$ EPR signal. Strong yellow luminescence can also be observed at low temperature, as shown in the inset of Fig. 3(a). Lack of green photoluminescence in the sample prepared by chemical method is in agreement with the previously reported result. ${ }^{17}$ Yellow emission in $\mathrm{ZnO}$ has been attributed to oxygen interstitials $\mathrm{O}_{\mathrm{i}}{ }^{15,18,23}$ Donor-acceptor recombination at lithium acceptors was also 

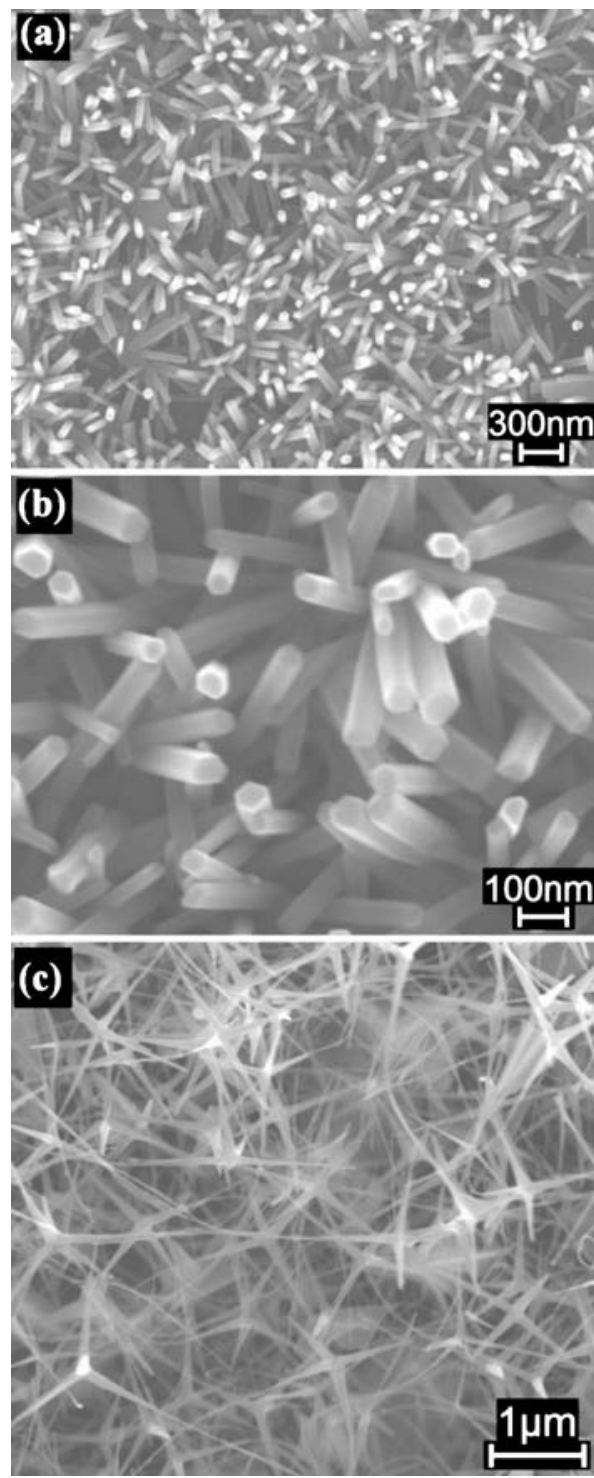

FIG. 1. Representative SEM images of $\mathrm{ZnO}$ nanostructures: (a) $\mathrm{ZnO}$ prepared by chemical methods, small magnification; (b) $\mathrm{ZnO}$ prepared by chemical methods, large magnification, and (c) $\mathrm{ZnO}$ prepared from $\mathrm{Zn}$ in humid argon flow.

proposed as the origin of the yellow emission. ${ }^{28,29}$ The correlation between the yellow emission and $g \sim 1.96$ EPR signal intensities was previously observed in $\mathrm{Al}$ doped $\mathrm{ZnO}$ samples. ${ }^{19}$ This is in contradiction with the results reported by Vanheusden et al. ${ }^{1,2}$ who found the correlation between green photoluminescence and $g \sim 1.96$ EPR signal.

Out of the four samples investigated here, the sample with the strongest $g \sim 1.96$ EPR signal exhibits yellow PL

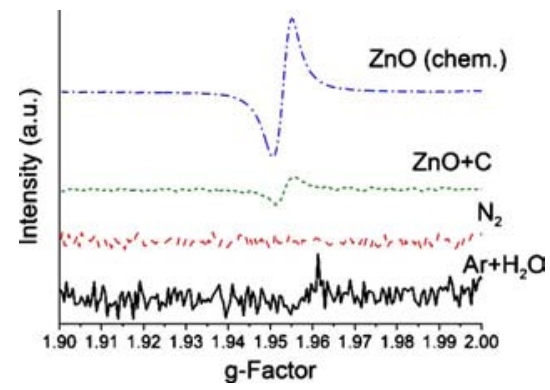

FIG. 2. EPR spectra measured at room temperature from $\mathrm{ZnO}$ structures using different methods. EPR spectra have been vertically shifted for clarity.
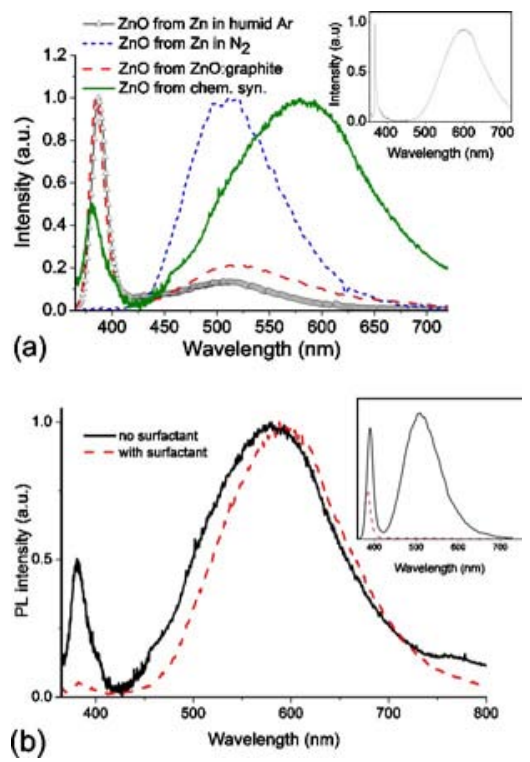

FIG. 3. (a) Photoluminescence spectra measured at room temperature from $\mathrm{ZnO}$ structures using different methods. The inset shows the PL from the sample fabricated by a chemical method at $4 \mathrm{~K}$. (b) The comparison of the photoluminescence spectra with and without surfactant for $\mathrm{ZnO}$ prepared by a chemical method. The inset shows the influence of surfactant for $\mathrm{ZnO}$ fabricated from $\mathrm{Zn}$ in humid argon flow.

emission. The sample with the strongest green PL emission ( $\mathrm{ZnO}$ tetrapod/nanowire structures fabricated in nitrogen flow) shows no EPR signal at all. The sample fabricated from $\mathrm{ZnO}$ :graphite mixture shows small EPR signal at the same position as the sample fabricated by chemical methods, but it exhibits green photoluminescence. The sample fabricated from $\mathrm{Zn}$ in humid argon flow also shows green photoluminescence, though it is much weaker compared to the sample fabricated in $\mathrm{N}_{2}$ gas flow. This sample possibly exhibits some feature at $g \sim 1.96$ near the level of noise. The interpretation of the obtained results is further complicated by the fact that $g=1.96$ EPR signal actually can consist of two lines $g=1.955$ and $g=1.958$ which may be caused by different defects. ${ }^{26}$ The samples exhibiting green and yellow emission investigated here show EPR signal at the same position $g \approx 1.955$, which has been previously assigned to $\mathrm{Zn}_{i}{ }^{25}$ Also, recent experiments on the influence of the electric field to the green luminescence in $\mathrm{ZnO}$ single crystals indicated that the luminescence may be due to complex defects including $\mathrm{Zn}_{i}{ }^{30}$ Another alternative explanation is that the $g \sim 1.955$ signal is caused by free electrons, while $g$ $\sim 1.958$ is caused by $\mathrm{Zn}_{i}$ or dislocations. ${ }^{26}$ Regardless of the cause of this signal, it is obvious that there is no simple relationship between the intensity of $g \sim 1.96 \mathrm{EPR}$ signal and visible photoluminescence. A possible explanation for this controversy is that two different deep levels are responsible for green and yellow photoluminescence. Transitions between conduction band electrons or shallow donors (depending whether there is any $g \sim 1.96$ EPR signal) and the deep level would result in the visible photoluminescence. If the deep level concentration is higher than a shallow donor concentration, this would explain the correlation between the $g$ $\sim 1.96$ EPR signal intensity and the visible PL (green or yellow, depending on the deep level involved) observed in some of the samples. The deep level involved in the yellow luminescence is likely interstitial oxygen, ${ }^{15,17,18,23}$ which is in agreement with the reported results on disappearance of this
AlP license or copyright, see http://apl.aip.org/apl/copyright.jsp 
emission after annealing in reducing atmospheres. ${ }^{17}$ Dependence of the visible emission (green or yellow) on the oxidation temperature in $\mathrm{ZnO}$ films prepared by thermal oxidation is also in agreement with intrinsic defect hypothesis. ${ }^{22}$ However, it should be noted that even though $\mathrm{ZnO}$ rods in this work have not been intentionally doped, presence of $\mathrm{Li}$ impurity in the starting material and hence $\mathrm{Li}$ acceptor related yellow luminescence ${ }^{28,29}$ is possible. The nature of the defect responsible for the green emission requires further study.

In order to obtain more information on the origins of green and yellow emission, fabricated nanostructures were coated with a surfactant using following procedure. $\mathrm{ZnO}$ nanostructures were dispersed in a dichloromethane solution of $n$-hexyltrichlorosilane in an ultrasonic bath for $1 \mathrm{~h}$. After dispersion, nanostructures were separated using centrifuge and rinsed thoroughly with dichloromethane to remove any residual surfactant and dried in a vacuum oven for $30 \mathrm{~min}$. After coating with surfactant, SEM and EDX were performed to check the morphology and composition. It was found that the morphology was preserved, and EDX confirmed presence of $\mathrm{Si}$ and $\mathrm{Cl}$ indicating successful attachment of $n$-hexyltrichlorosilane to $\mathrm{ZnO}$ nanostructures. The comparison between PL spectra of $\mathrm{ZnO}$ nanostructures fabricated by chemical methods with and without surfactant is shown in Fig. 3(b). The inset shows the effects of surfactant for $\mathrm{ZnO}$ nanostructures fabricated in humid argon flow. It can be observed that the addition of surfactant significantly reduces green emission, indicating that the defects responsible for the green emission are located at the surface. On the other hand, yellow emission is not reduced by surfactant coating. Small red shift of the peak can be observed, which is likely due to the suppression of the green part of the emission. This indicates that the yellow centers are not located on the surface, which is in agreement with the previous results for $\mathrm{ZnO}$ samples sintered in moist air. ${ }^{15}$ Also, coating of $\mathrm{ZnO}$ single crystals with $\mathrm{KCl}$ or $\mathrm{KI}$ also resulted in the suppression of green luminescence while yellow emission remained. ${ }^{14}$

To summarize, we have performed PL and EPR spectroscopy studies of $\mathrm{ZnO}$ structures fabricated by different methods. We found that the fabrication methods significantly affected the properties of the obtained nanostructures. Those fabricated by evaporation methods exhibited green PL from surface centers. The ratio of the UV to green emission, as well as the existence of $g=1.96$ EPR signal, were dependent on the fabrication atmosphere and the starting material ( $\mathrm{Zn}$ vs $\mathrm{ZnO}: \mathrm{C}$ mixture), but no correlation was observed between EPR and green PL. The nanostructures fabricated by chemical methods exhibited yellow luminescence and strong $g$ $=1.96$ EPR signal. Yellow luminescence was not sensitive to the surface modifications of the nanostructures, hence it likely originated from the defects in the bulk, not the surface.
The authors would like to thank Amy Wong and Wing Song Lee for SEM measurements, and Dr. J. Gao for XRD measurements. This work is supported by the University Research Committee Seed Funding Grant of the University of Hong Kong.

${ }^{1}$ K. Vanheusden, C. H. Seager, W. L. Warren, D. R. Tallant, and J. A. Voigt, Appl. Phys. Lett. 68, 403 (1998).

${ }^{2}$ K. Vanheusden, W. L. Warren, C. H. Seager, D. R. Tallant, J. A. Voigt, and B. E. Gnade, J. Appl. Phys. 79, 7983 (1996).

${ }^{3}$ N. Y. Garces, L. Wang, L. Bai, N. C. Giles, L. E. Halliburton, and G. Cantwell, Appl. Phys. Lett. 81, 622 (2002).

${ }^{4}$ R. Dingle, Phys. Rev. Lett. 23, 579 (1969).

${ }^{5}$ D. C. Reynolds, D. C. Look, B. Jogai, and H. Morkoç, Solid State Commun. 101, 643 (1997).

${ }^{6}$ S. A. Studenikin and M. Cocivera, J. Appl. Phys. 91, 5060 (2002).

${ }^{7}$ D. C. Reynolds, D. C. Look, and B. Jogai, J. Appl. Phys. 89, 6189 (2001).

${ }^{8}$ S. A. Studenikin, N. Golego, and M. Cocivera, J. Appl. Phys. 84, 2287 (1998).

${ }^{9}$ V. A. L. Roy, A. B. Djurišić, W. K. Chan, J. Gao, H. F. Lui, and C. Surya, Appl. Phys. Lett. 83, 141 (2003).

${ }^{10}$ Y. G. Wang, S. P. Lau, H. W. Lee, S. F. Yu, B. K. Tay, X. H. Zhang, and H. H. Hng, J. Appl. Phys. 94, 354 (2003).

${ }^{11}$ A. van Dijken, E. Meulenkamp, D. Vanmaekelbergh, and A. Meijerink, J. Phys. Chem. B 104, 1715 (2000).

${ }^{12}$ A. van Dijken, E. Meulenkamp, D. Vanmaekelbergh, and A. Meijerink, J. Lumin. 90, 123 (2000).

${ }^{13}$ B. Lin, Z. Fu, and Y. Jia, Appl. Phys. Lett. 79, 943 (2001).

${ }^{14}$ Y. Harada and S. Hashimoto, Phys. Rev. B 68, 045421 (2003).

${ }^{15}$ M. Liu, A. H. Kitai, and P. Mascher, J. Lumin. 54, 35 (1992).

${ }^{16}$ A. Wood, M. Giersig, M. Hilgendorff, A. Vilas-Campos, L. M. LizMarzán, and P. Mulvaney, Aust. J. Chem. 56, 1051 (2003).

${ }^{17}$ L. E. Greene, M. Law, J. Goldberger, F. Kim, J. C. Johnson, Y. Zhang, R. J. Saykally, and P. Yang, Angew. Chem., Int. Ed. 42, 3031 (2003).

${ }^{18}$ X. L. Wu, G. G. Siu, C. L. Fu, and H. C. Ong, Appl. Phys. Lett. 78, 2285 (2001).

${ }^{19}$ N. Ohashi, T. Nakata, T. Sekiguchi, H. Hosono, M. Mizuguchi, T. Tsurumi, J. Tanaka, and H. Haneda, Jpn. J. Appl. Phys., Part 2 38, L113 (1999).

${ }^{20}$ S. Monticone, R. Tufeu, and A. V. Kanaev, J. Phys. Chem. B 102, 2854 (1998).

${ }^{21}$ A. B. Djurišić, Y. H. Leung, W. C. H. Choy, K. W. Cheah, and W. K. Chan, Appl. Phys. Lett. 84, 2635 (2004).

${ }^{22}$ Y. G. Wang, S. P. Lau, X. H. Zhang, H. W. Lee, S. F. Yu, B. K. Tay, and H. H. Hng, Chem. Phys. Lett. 375, 113 (2003).

${ }^{23}$ X. L. Wu, G. G. Siu, C. L. Fu, and H. C. Ong, Appl. Phys. Lett. 78, 2285 (2001).

${ }^{24}$ N. Y. Garces, N. C. Giles, L. E. Halliburton, G. Cantwell, D. B. Eason, D. C. Reynolds, and D. C. Look, Appl. Phys. Lett. 80, 1334 (2002).

${ }^{25}$ F. Morazzoni, R. Scotti, P. Di Nola, C. Milani, and D. Narducci, J. Chem. Soc., Faraday Trans. 88, 1691 (1992).

${ }^{26}$ W. Hirschwald, P. Bonasewicz, L. Ernzt, M. Grade, D. Hoffmann, S. Krebs, R. Littbarski, G. Neumann, M. Grunze, D. Kolb, and H. J. Schulz, in Current Topics in Materials Science, edited by E. Kaldis (NorthHolland, Amsterdam, 1981), Vol. 7, Chap. 3.

${ }^{27}$ S. B. Zhang, S.-H. Wei, and A. Zunger, Phys. Rev. B 63, 075205 (2001).

${ }^{28}$ D. Zwingel, J. Lumin. 5, 385 (1972).

${ }^{29}$ O. F. Schirmer and D. Zwingel, Solid State Commun. 8, 1559 (1970).

${ }^{30}$ N. O. Korsunska, L. V. Borkovska, B. M. Bulakh, L. Yu. Khomenkova, V. I. Kushnirenko, and I. V. Markevich, J. Lumin. 102-103, 733 (2003). 